Int. J. Dev. Biol. 58: 239-246 (2014)

doi: $10.1387 / \mathrm{ijdb} .130341 \mathrm{mp}$

\title{
BMP4 regulation of human trophoblast development
}

\author{
YINGCHUN LI ${ }^{1,2}$ and MANA M. PARAST ${ }^{*, 1,2}$ \\ ${ }^{1}$ Department of Pathology and ${ }^{2}$ Sanford Consortium for Regenerative Medicine, University of California San Diego, \\ La Jolla, CA
}

\begin{abstract}
Since the derivation of human embryonic stem cells, and the subsequent generation of induced pluripotent stem cells, there has been much excitement about the ability to model and evaluate human organ development in vitro. The finding that these cells, when treated with BMP4, are able to generate the extraembryonic cell type, trophoblast, which is the predominant functional epithelium in the placenta, has not been widely accepted. This review evaluates this model, providing comparison to early known events during placentation in both human and mouse and addresses specific challenges. Keeping in mind the ultimate goal of understanding human placental development and pregnancy disorders, our aim here is two-fold: to distinguish gaps in our knowledge arising from mis- or over-interpretation of data, and to recognize the limitations of both mouse and human models, but to work within those limitations towards the ultimate goal.
\end{abstract}

KEY WORDS: trophoblast, placenta, BMP4, stem cells

\section{Introduction}

Early development of the human placenta is mostly a black box. Most of what we know about the early stages in formation of this important organ comes from images from the limited number of samples in the Boyd and Carnegie Collections (recently reviewed in James et al., 2012a,b). While intriguing, these images fall short of conclusive evidence which can be gathered from both in vitro and in vivo manipulation of embryos in animal models. For this reason, much of the scientific knowledge about early embryonic (and placental) development comes from intricate studies in rodent models; at times, based on little more than assumption, these data are taken to be fully representative of early human development.

Over the past decade, the establishment and widespread availability of human pluripotent stem cell (hPSC) lines-both derived from embryos (human embryonic stem cells/hESCs) and subsequently by reprogramming of somatic cells (human induced pluripotent stem cells/hiPSCs) - has opened a new chapter in the study of early human development. The early observation of trophoblast differentiation following BMP4 treatment of human embryonic stem cells by Jamie Thomson's group extended this opening to placental biologists (Xu etal., 2002). Since then, multiple groups have used this model to probe the mechanisms of human trophoblast lineage specification and differentiation. Nevertheless, this model remains under-appreciated by most reproductive biologists and the wider stem cell research community.

The goal of this review is to highlight the knowledge gained about trophoblast differentiation through the use of hPSCs, including hESCs and hiPSCs. Comparison to mouse embryonic (mESC) and mouse trophoblast stem cell (mTSC) differentiation and placental development will be made to highlight similarities as well as differences. Ultimately, however, as with differentiation of hPSCs to any other cell type, comparison to primary human cells and tissues is required to determine the true identity of in vitro-derived cells. Hence, we will begin with a brief overview of human trophoblast differentiation, with a focus on early placentation.

\section{Early human placental development}

Early following attachment to the endometrium, the human blastocyst implants and becomes fully surrounded by decidualized endometrial stroma. At this stage, two trophoblast populations are present in the primitive placenta: a mononuclear "cytotrophoblast" (CTB) and a multinucleated "syncytium" (James et al., 2012a). Aside from morphology, little is known about these particular cell types, their markers and function. While the Ki67+ CTB is taken to be the proliferative "stem" cell type, the primitive syncytium, which

\footnotetext{
Abbreviations used in this paper: BMP4, Bone morphogenetic protein 4; CDX2, caudal-type homeobox-2; CTB, cytotrophoblast; ESC, embryonic stem cell; EVT, extravillous trophoblast; ExE, extraembryonic ectoderm; FCM, feeder-conditioned media; FGF, fibroblast growth factor; hCG, human chorionic gonadotropin; ICM, inner cell mass; iPSC, induced pluripotent stem cell; PSC, pluripotent stem cell; STB, syncytiotrophoblast; TE, trophectoderm; TSC, trophoblast stem cell.
}

\footnotetext{
*Address correspondence to: Mana M. Parast. Sanford Consortium for Regenerative Medicine, Department of Pathology, University of California San Diego 9500 Gilman Drive, MC 0695, La Jolla, CA 92093, USA.Tel: (858)-534-8631. Fax: (858)-246-1586. Email: mparast@ucsd.edu
}

Final, author-corrected PDF published online: 8 July 2014.

ISSN: Online 1696-3547, Print 0214-6282 
appears to digest away the decidua at the leading edge of the implanting embryo, potentially acts in an "invasive" capacity. Such multinucleated "invasive" trophoblast, present in early implantation sites, are sometimes also referred to as "giant" cells (James et al., 2012a) (see Fig. 1B below). For this reason, it is at times mistakenly assumed that these cells are equivalent to invasive mouse trophoblast of the same name, which arise by endoreduplication (John and Hemberger, 2012). The primitive syncytium forms fluid-filled spaces, called lacunae, which breach maternal sinusoids, thereby allowing flow of maternal blood directly to the growing embryo (James et al., 2012a).

The exact nature of the primitive syncytium, the mechanism of its formation, and its functional capacity to invade and/or erode tissue has not been determined. In addition, its relationship to the definitive syncytium, the multinucleated cell layer abutting maternal sinusoids, and later, the intervillous space, is also unclear. The definitive syncytiotrophoblast (STB), first noted at day 15 of gestation (Fig. 1A), is thought to arise by fusion of CTB to line the maternal sinusoids. Thereafter, the STB grows by continuous fusion of underlying CTB (James et al., 2012a).

True invasive extravillous trophoblasts (EVTs) appear to arise from anchoring villi, differentiating from cytotrophoblast cell columns (Fig. 1B). These cells invade through the uterine wall (interstitial EVT) and remodel maternal spiral arterioles (endovascular EVT) (Knofler, 2010; James et al., 2012a; Soares et al., 2012). The regulation of differentiation of this lineage as well as their invasive capacity are pivotal to understanding pregnancy loss and complications, including the pregnancy-induced hypertensive syndrome, preeclampsia (Knofler, 2010; Soares et al., 2012). These cells are known to lose proliferative capacity as they gain invasive potential (Knofler, 2010; James et al., 2012a; Soares et al., 2012). Intricate communication with surrounding cells, particularly decidua and the immune-modulatory cells infiltrating this tissue, is central to establishment of the "proper" level of uterine invasion (Gellersen et al., 2007; Bulmer et al., 2010). In fact, poor decidualization (as seen, for example, in cases of implantation in the lower uterine segment - "previa") is associated with abnormally adherent placentation ("creta"), which often requires removal of the in-situ placenta by hysterectomy (Wortman and Alexander, 2013).

Outside the implantation site, EVT also exist in fetal membranes as well as in the trophoblast "islands" in the placental disc proper (Lee et al., 2007) (Fig. 1C-D). How these EVT subtypes differ from their basal plate counterparts remains to be elucidated.

\section{Characteristics of different trophoblast sub-lineages}

Multiple markers are routinely used to highlight different trophoblast subtypes. While cytokeratin 7 (KRT7) is used as a pan-trophoblast marker starting from the blastocyst stage of human development (Niakan and Eggan, 2013), EGFR and CAD1 (Ecadherin) are often used to highlight CTB (Ferretti et al., 2007), and in fact can be used to sort out this cell population out of human placental cell preps with high specificity. EVT are specifically characterized by surface expression of HLA-G, although soluble forms are also noted in CTB (Rizzo et al., 2011). CTB and EVT have been further defined based on integrin expression, with CTB expressing $\alpha_{6} \beta_{4}$, proximal column EVT expressing $\alpha_{5} \beta_{1}$ and distal column and invasive EVT expressing $\alpha_{1} \beta_{1}$ integrins (Damsky et al., 1992). The STB compartment is defined by secretion of the pregnancy hormones hCG and hPL (Fujimoto et al., 1986; Cole, 2012); however, two caveats must be considered here. First, hCG is secreted in multiple forms, including a hyperglycosylated form (H-hCG) which was determined to be secreted primarily by early invasive trophoblast (Handschuh et al., 2007; Guibourdenche et al., 2010; Cole, 2010, 2012); whether this includes the primitive syncytium is unknown, while villous STB are known to be negative for this marker (Handschuh et al., 2007). Second, placental lactogen (hPL, also known as chorionic somatomammotrophin/CSH), also a characteristic marker of STB, is secreted by more mature STB, with expression increasing with increasing gestational age (Fujimoto et al., 1986).

Few lineage-specific transcription factors which can differentiate between villous and extravillous trophoblast subtypes have been described in the human placenta. One such factor, CTBspecific p63, is described below. ID2 has also been identified as CTB specific (Janatpour et al., 2000), while ASCL2 is enriched in cell column trophoblast and EVT (Meinhardt et al., 2005; Murthi et al., 2013). Other transcription factors, including the homeobox genes $D L X 3$ and $D L X 4$ have been identified in both villous and extravillous trophoblast (Murthi et al., 2013). We recently identified the pluripotency factor, KLF4, to be expressed in villous STB (Li et al., 2013). Wnt-activated TCF4 has been suggested to play a role in formation of EVT (Knofler and Pollheimer, 2013); however, TCF4 has also been identified to play a role in fusion of human

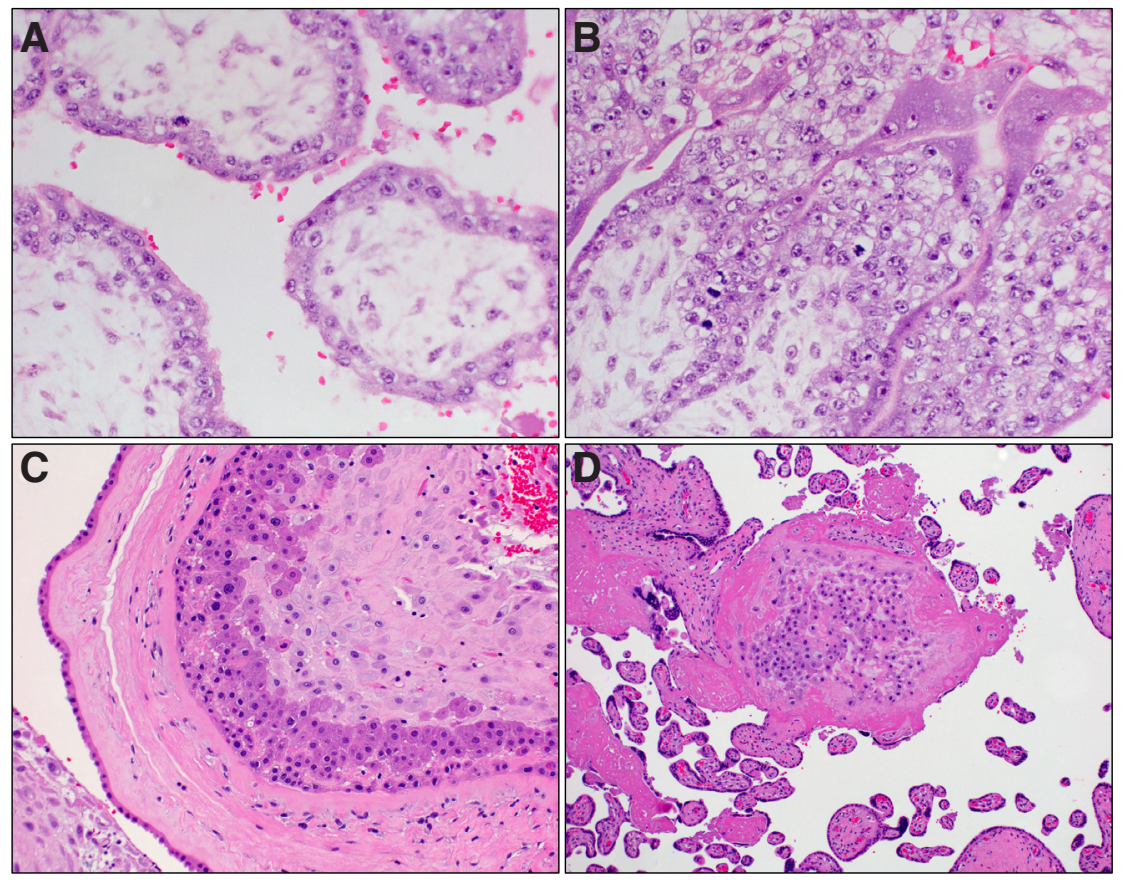

Fig. 1. H\&E staining of early placenta tissue, from a rare archived 16-day human blastocyst specimen. (A) Continuous STB layer covering underlying CTB layer. (B) Column CTB and a few multinucleated "giant cells." Some EVT also exist in chorionic (fetal) membranes (C) and intraplacental trophoblastic islands (D). 


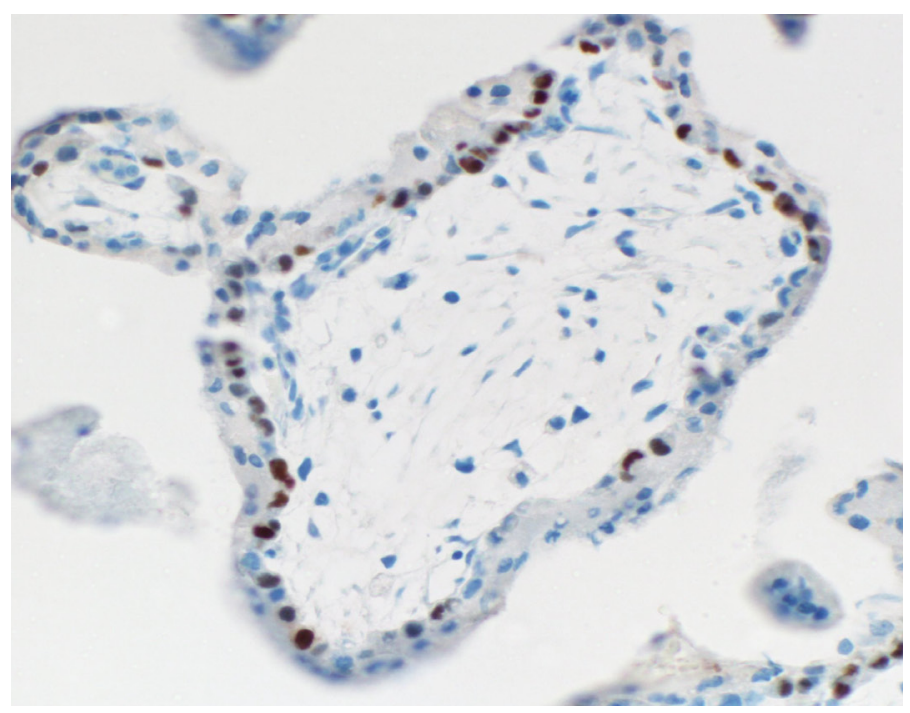

Fig. 2. Immunohistochemical staining for CDX2 in early (7-week) placental tissue. CDX2 (brown) is expressed only in a subset of CTBs. The tissue section is counterstained with hematoxylin (b/ue).

choriocarcinoma cells (Matsuura et al., 2011), so its specificity to the EVT lineage remains to be confirmed. Other transcription factors, such as PPAR $\gamma$, are expressed in all trophoblast, although activation of PPAR $\gamma$ has been associated specifically with inhibition of trophoblast invasion (Fournier et al., 2011). Overall, the majority of studies are based on detection of RNA, either by RT-PCR or in-situ hybridization; detection of the corresponding proteins are more difficult due to lack of high-quality reagents. For example, GCM1, which is thought to regulate villous branching and CTB fusion, is thought to be confined to a subgroup of CTB (Baczyk et al., 2009), although different antibodies and staining methodologies show different staining patterns (Genbacev et al., 2011; compare to STB staining on the Human Protein Atlas website).

In order to determine whether an in vitro model is representative of human trophoblast differentiation in vivo, detailed analysis of the various trophoblast subtypes, at various times during gestation, is required. In one such study (Lee et al., 2007), we showed that p63, a member of the p53 family of nuclear proteins, marks all proliferative CTB at all gestational ages in the human placenta; this marker is lost when CTB differentiate, either into EVT or multinucleated STB. In addition, by immunohistochemistry, we determined the exact pattern of expression of several trophoblast-associated markers, including MelCAM and inhibin: while the former is confined to mature EVT, the latter is expressed in both EVT and STB (Lee et al., 2007). More such studies are needed to probe differential marker expression between trophoblast cell types in-situ.

\section{The trophoblast stem cell niche}

Mouse trophoblast stem cells are typically derived from E3.5 blastocysts, using a combination of feeders and FGF4 (Tanaka et al., 1998). These cells are characterized by expression of multiple transcription factors, including Cdx2, Elf5, and Eomes (Roberts and Fisher, 2011; John and Hemberger, 2012). When plated in the absence of feeders (or feeder-conditioned medium) and FGF4, these cells lose the above stem cell markers, and begin to express markers of both labyrinthine (villous) trophoblast and trophoblast giant cell (EVT) lineages (Tanaka et al., 1998). When injected into blastocysts, mouse TS cells are able to contribute to all trophoblast sublineages in vivo (Tanaka et al., 1998).

Whether a similar "TS" population exists in the human placenta is unknown. While human blastocysts do express CDX2 specifically in the trophectoderm (Niakan and Eggan, 2013), derivation of TS cells from human embryos has so far been unsuccessful (Rossant, 2007; Genbacev et al., 2011). ELF5 has been identified in a subset of first trimester CTB (Hemberger et al., 2010), suggesting that the post-implantation placenta may harbor such TS cells. We have recently confirmed the presence of CDX2 in a subset of first trimester CTB (Fig. 2), providing more evidence for the latter hypothesis. However, whether these cells would be truly bipotential, or whether EVT and STB each arise from their own independent precursor cell types, remains controversial (Knofler 2010). Finally, the non-trophoblast (mesoderm-derived) portion of the human chorion has also been proposed as a TS cell niche, with cell lines derived using a combination of FGF and activin/ nodal inhibitors (Genbacev et al., 2011); however, the true nature of these cells remains to be independently confirmed.

While defining the human TS cell niche remains an important issue, the more difficult question may be how to maintain such cells in vitro. Mouse TS cells require a combination of FGF and activin signaling in order to maintain their multipotent state (Tanaka et al., 1998; Erlebacher et al., 2004). The majority of studies, however, use feeder-conditioned media (FCM), in combination with FGF4, to derive and maintain these cells. The requirement of $20 \%$ fetal bovine serum has made it difficult to develop defined media for these cells. Interestingly, undifferentiated mouse TS cells also secrete BMP4 (Murohashi et al., 2010) and express BMP receptors, including Bmpr1a and Bmpr2 (Kishigami and Mishina, 2005); however, the role of this signaling in maintenance and/or differentiation of mouse TS cells remains entirely unknown (see below). Culture on tissue culture plastic in low oxygen inhibits differentiation of mouse TS cells (Tache et al., 2013), while culture on a fibronectin-rich matrix in hypoxia promotes formation of giant cells (Choi et al., 2013).

Turning to the human placenta, isolated CTB rapidly lose their proliferative capacity in vitro (Bilban et al., 2010; Knofler 2010). For this reason, STB-denuded first trimester placental explants have been used at times for evaluation of CTB proliferation, confirming the importance of the underlying stroma in this process (Baczyk et al., 2006; Forbes et al., 2008; Knofler 2010). Both models are suboptimal for evaluation of CTB proliferation; nevertheless, studies with the latter model have suggested a role for IGF and FGF signaling, through the MAPK pathway, in promoting CTB proliferation (Baczyk et al., 2006; Forbes et al., 2008). Conversely, TGF $\beta$ signaling has been shown to inhibit CTB proliferation (Graham et al., 1992; Pollheimer and Knofler 2005). BMP signaling has not been explored in human CTB, although we have confirmed the expression of both ligands and receptors in first trimester placental explants and CTB (Parast et al., unpublished data). The maintenance of CTB proliferation in vivo is likely much more complex, and dependent on crosstalk between these and other signaling pathways, with concomitant regulation of cell survival, differentiation, and invasion (Knofler 2010). It is clear, however, that the number of proliferative CTB is drastically diminished in the latter half of pregnancy, and also relatively well-accepted that later gestation CTB have a reduced ability to differentiate into EVT. This seriously limits the study of both the human "TS" cell niche 
and the disease-relevant EVT to those researchers with access to first trimester placental tissues.

\section{BMP4 and induction of the trophoblast lineage in human pluripotent stem cells}

Human ESCs were first found to differentiate into trophoblast following BMP4 treatment over ten years ago (Xu et al., 2002). In this original study, BMP4 was added to hESCs in the presence of feeder-conditioned media (FCM) as well as bFGF, and cells were found to flatten, form multinucleated cells, express trophoblastassociated genes based on microarray analysis, and secrete hCG, estradiol, and progesterone (Xu et al., 2002). Similar differentiation was said to occur in the absence of FCM/bFGF; however, it was more asynchronous (Xu et al., 2002). This study was followed by two others, by independent groups, the first showing induction of EVT-like cells (based on HLA-G expression), in addition to multinucleated syncytiotrophoblast-like cells, following similar BMP4 treatment (Das et al., 2007), and the second showing a similar differentiation pattern following treatment, in presence of FCM, with an inhibitor of activin/nodal signaling, instead of BMP4 (Wu et al., 2008).

Since then, additional studies have refined culture conditions for trophoblast differentiation, finding that BMP4-induced differentiation into the trophoblast lineage is in fact more uniform in the absence of bFGF (Das et al., 2007, Yu et al., 2011), and even in minimal media without FCM (Erb et al., 2011). Most recently, it has been shown that additional inhibitors of FGF (Sudheer et al., 2012) and activin/nodal signaling (Amita et al., 2013) during BMP4 treatment unidirectionally differentiate hESCs into trophoblast. That signaling through the BMP4 receptors is involved in differentiation of this lineage is supported by a study showing that hESC lines with a deficiency in the phosphatidyl-inositol-glycan class $\mathrm{A}(P I G-A)$ gene cannot differentiate into trophoblast (Chen et al., 2008). PIG-A is required for the synthesis of glycosyl-phosphatidyl-inositol (GPI)anchored proteins, including BMP coreceptors.

Multiple other groups have used the BMP4 model to further evaluate the early steps in human trophoblast differentiation. Drukker et al., (2012) were able to isolate $\mathrm{APA}^{+}$syncytiotrophoblast precursors from BMP4-treated hESC cultures, while Marchand et al., (2011) applied transcriptomic analysis of these cells to identify novel genes involved in trophoblast differentiation. In fact, by comparative analysis of human trophectoderm (TE) samples, Bai et al., (2011) have found that BMP4-treated hESCs indeed express TE-specific transcription factors, confirming the utility of this model for study of early lineage specification. In addition, Chen et al., (2013), among others, have shown that hiPSCs behave similarly to hESCs when treated with BMP4. Finally, as hinted in the original study of Xu et al., (2002), Lichtner et al., (2013) have now shown that other BMP family members can also induce the trophoblast lineage, with BMP10, being most resistant to inhibition by NOGGIN, as the most potent.

Although the focus of this review is on BMP4 signaling, it should be mentioned here that induction of trophoblast from hESCs has also been noted following culture of hESC-derived embryoid bodies on Matrigel, with slightly different gene expression profile, but essentially the same final conclusion: that these cells retain the ability to differentiate into this extraembryonic cell type (Giakoumopoulos and Golos, 2013).

\section{Challenges to the BMP4 Model}

The trophoblast differentiation potential of hESCs was at first surprising, since LIF-dependent mouse ES cells rarely contribute to the trophectoderm compartment when injected into blastocysts (Beddington and Robertson, 1989; Nagy et al., 1990). In fact, BMP4 signaling is required for maintenance of pluripotency in mESCs (Ying et al., 2003). Nevertheless, mESCs have been shown to differentiate into trophoblast in vitro, when cultured either on laminin in serum-free media containing BMP4 (Hayashi et al., 2010) or when differentiated on collagen IV (Schenke-Layland et al., 2007). The latter study found the trophoblast differentiation potential to be confined to feeder-dependent mESC lines and to be dependent on $C d x 2$. More recently, mouse epiblast stem cells (mEpiSCs) were derived from post-implantation embryos. These cells require FGF and activin signaling to maintain their pluripotency and have the unusual property of expressing $C d x 2$ and forming "giant cells" following BMP4 treatment (Brons et al., 2007; Tesar et al., 2007). This was deemed consistent with trophoblast differentiation potential, which came to be accepted as a characteristic which distinguishes these cells from mESCs. However, the exact nature of BMP4-treated mEpiSCs is not clear. First, a "TS" cell state has not been identified. Second, aside from $C d x 2$, other more specific mouse trophoblast-associated markers such as Tpbpa, have yet to be demonstrated in these cells.

More recently, based partially on the above data, Bernardo et al., (2011) challenged the premise of BMP4-induction of the trophoblast lineage from hESCs, stating that BMP4 is known mainly as an inducer of the mesoderm lineage. In fact, short term BMP4 treatment of hESCs has been shown to induce mesoderm (Zhang et al., 2008), and authors of the above studies on BMP4-induced trophoblast differentiation have noted induction of some mesoderm markers (including T/BRACHYURY) alongside trophoblast markers, particularly at early timepoints following BMP4 treatment (Xu et al., 2002; Yu et al., 2011). Using CDX2 expression as the main marker of the trophoblast lineage, Bernardo et al., (2011) showed that knockdown of BRACHYURY abrogated CDX2 expression following BMP4 treatment. They concluded that this result is consistent with the BMP4-treated cells being in fact of mesodermal, and not trophectodermal, origin. They correctly pointed to the fact that, in the mouse embryo, $C d x 2$ is also expressed in early mesoderm tissue and that, by itself, is not specific to trophectoderm (Chawengsaksophak etal., 2004). They also challenged the nature of BMP4-treated mEpiSCs, again pointing to $C d x 2$ being used as the sole indicator for trophoblast differentiation. They reason that mEpiSCs, being derived from the post-implantation embryo, should not be able to "go backward" and differentiate into trophoblast. Since hESCs show an epigenetic profile more similar to "primed" mEpiSCs than "ground state" mESCs (Nichols and Smith, 2012; De Los Angeles et al., 2012), Bernardo et al., thus extended the above reasoning to hESCs, emphasizing that these cells also should not have the capacity to differentiate into trophoblast.

However intriguing, the major conclusions of this study are based on several assumptions. The first is the specificity of the marker BRACHYURY. This gene is in fact first expressed in extraembryonic ectoderm (ExE), the compartment which houses trophoblast stem cells in the mouse, at E5.5, before gastrulation even begins (Rivera-Perez and Magnuson, 2005). In fact, both BRACHYURY RNA and protein are expressed in the ExE in the 
early post-implantation period (Rivera-Perez and Magnuson, 2005; Inman and Downs, 2006). However, to date, no studies have been done to determine the role of BRACHYURY in the ExE or mouse TS cells. We have found that Brachyury RNA is in fact expressed in undifferentiated mouse TS cells and decreases with differentiation in vitro (Parast et al., unpublished data). Given this expression pattern, it remains plausible that Brachyury would be involved in maintenance of the undifferentiated TS cell state, perhaps by regulating $C d x 2$.

Second is the assumption that BMP4 signaling does not play a role in the ExE compartment. In fact, as mentioned above, several BMP receptor genes, including Bmpr1a, are expressed in the ExE (Kishigami and Mishina, 2005); the ExE is also known to secrete BMP4 which initiates formation of the primitive streak in the early post-implantation embryo (Murohashi et al., 2010). Embryos deficient in Bmpr1a do implant; however, they die in the early post-implantation period, with several abnormalities (Mishina et al., 1995). While it is assumed that this phenotype is due only to abnormalities in the embryonic compartment, it should be noted that the extraembryonic compartment in these embryos is also abnormal, missing both Brachyury and Eomes expression from the ExE (Di-Gregorio et al., 2007). While the function of Brachyury in the ExE is yet to be investigated, it is known that Eomes plays a major role in the maintenance of this compartment (Russ et al., 2000), pointing to the plausible explanation that signaling through Bmpr1a may be required in ExE maintenance. Based on these examples of Brachyury and Bmpr1a, it is apparent that further studies are needed in order to probe the roles of these genes in the ExE, and that lack of data in this area should not be taken as negative data.

Third is the overarching assumption that early mouse and human development are highly similar. In fact, despite the known similarities, when it comes to trophoblast lineage specification and placental development, the rule is one of divergence. While the trophoblast lineage is specified early in the mouse preimplantation embryo, with reciprocal expression of POU5F1/OCT4 and CDX2 in the inner cell mass and TE, respectively, the human embryo shows a lag in trophoblast lineage segregation, with a period of time during which OCT4 and CDX2 are coexpressed in the TE (Niakan and Eggan, 2013). In fact, the human OCT4 gene regulatory elements are more similar to those in rabbit and bovine, and divergent from mouse (Berg et al., 2011): bovine Oct4 constructs were not repressed when put into mouse TE, consistent with the observation that TE lineage commitment does not occur until later stages in cattle. Interestingly, similar to human, BMP4 has also been shown to induce the trophoblast lineage in rabbit ESCs (Tan et al., 2011) and used to establish trophoblast cell lines from bovine embryos (Suzuki et al., 2011). Similarly, X-chromosome inactivation in female embryos has recently been found to be divergent in rabbits and humans, compared to mice: while mice show inactivation of the paternal $X$ in early embryogenesis, with reversal of this process in the ICM followed by random inactivation in the ICM-derived epiblast, $X$ inactivation begins later in rabbit and human embryos and occurs in a high proportion of ICM cells in the blastocyst (Okamoto et al., 2011). This study casts doubt on statements of equivalency of mEpiSCs and hESCs based solely on their epigenetic profile and growth factor requirements.

Finally, in challenging the conclusions of Bernardo et al., (2011), a word regarding their culture conditions is required. Although this has been extensively discussed elsewhere (Ezashi et al., 2012) and comparative studies completed (Amita et al., 2013), the fact that the authors used chemically defined media, typically used for culture of mouse EpiSCs, has to be addressed here. These conditions are vastly different from any of the studies involving BMP4 and human ESCs published before or since. The addition of a PI3-kinase inhibitor is also curious; while it is justified as a factor which "enhances hESC differentiation," the cited manuscript describes a protocol for enhancing mesendoderm differentiation (McLean et al., 2007). The use of this inhibitor also ignores data from studies of primary human trophoblast, showing that the PI3kinase pathway is in fact involved in differentiation of the EVT lineage (Knofler 2010; Soares et al., 2012).

\section{Looking ahead: to BMP4 or not to BMP4?}

In order to determine whether the BMP4 model-or in fact any in vitro differentiation protocol applied to hESCs/iPSCs - is useful, it needs to be compared to human cells and tissues in vivo. We recently completed such a study of BMP4-treated hESCs, comparing them to a series of human fetal and placental cells and tissues (Li et al., 2013). Genome-wide expression analysis showed that the BMP4-treated cells are most closely related to isolated CTB from first trimester placental tissues, clustering away from mesoderm-derived amnion and placental stroma (Li et al., 2013). It should be pointed out that differ-

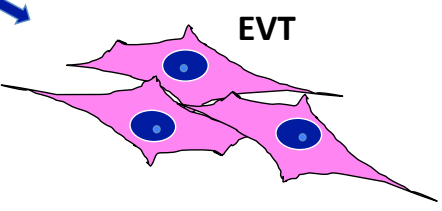

HLA-G/H-hCG
Fig. 3. Proposed model of BMP4-directed trophoblast differentiation of hPSCs. Self-renewing hPSCs are maintained under feeder-free conditions with bFGF. For trophectoderm differentiation, hPSCs are cultured in feeder-conditioned medium supplemented with $10 \mathrm{ng} / \mathrm{ml}$ BMP4 for up to 8 days. BMP4-treated hPSCs undergo a p63/KRT7/CDX2 triple-positive CTB "stem cell" state prior to terminal differentiation into HLA-G/H-hCG positive EVT and hCG/KLF4 positive STB. 
ences remained in gene expression profile between the primary and in vitro-generated cells, likely due to suboptimal "2D" culture conditions. We are currently working to enhance the in vitro conditions, using human placenta-derived extracellular matrix as well as screening for other useful growth factors and small molecules.

Whether the BMP4-hESC model can generate a bona-fide human "TS" cell also remains an open question. Given our limited understanding of this cell type and its niche, care should be taken to avoid use of a single marker to define this compartment, particularly markers which have yet to be validated in the human placenta. In our recently-published study of BMP4-treated hESC (Li et al., 2013), we used p63 as a marker of proliferative CTB, based on our previous study of human placental tissues at varying gestational ages (Lee et al., 2007). We showed that BMP4-treated

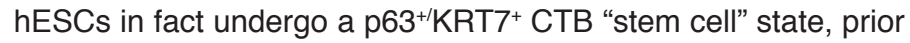
to differentiating into surface HLAG ${ }^{+}$EVT and hCG-secreting STB (Fig. 3), and that knockdown of p63 inhibited differentiation into these terminal lineages (Li et al., 2013). A subset of these p63+ cells were also positive for CDX2, again showing similarities to CTB in first trimester placenta ( $\mathrm{Li}$ et al., 2013). Our conclusionthat these hESC-derived cells are bona-fide trophoblast-was based, not just on p63 and CDX2 expression, but on the entirety of the experimental evidence, including comparison to primary CTB, based on genome-wide expression profiles, and functional assays (Li et al., 2013).

Going forward, much remains to be elucidated regarding human placental development, including the role of BMP4 signaling, trophoblast lineage specification and subtype-specific differentiation, and comparison to mouse and other animal models. The placenta overall remains a poorly-understood organ, even in the mouse, where the necessity of this compartment for embryonic growth and development remains under-appreciated; routine phenotyping of many transgenic mouse models, including those with embryonic lethality, are done with only a fleeting glance at the extraembryonic compartment. More thorough examination, including TE-specific knockdown in addition to wild-type tetraploid rescue, should be done to determine or exclude a role for an individual gene/protein in placental development and trophoblast differentiation. While gene-specific knockdown in the mouse remains the gold standard for evaluating the role of individual genes during embryonic and placental development, expression studies in primary human placental tissues and isolated CTBs should be performed to document similar expression and potential regulation in human tissues, prior to drawing conclusions about limitations of an hESC-based model. Careful gene expression profiling studies of human CTB, EVT, and STB are required in order to identify lineage-specific transcription factors, as well as specific signaling pathways involved in their maintenance and differentiation. Finally, continued research using both mouse and human pluripotent stem cells is required. Specifically, in the mouse, where such experimentation is possible, studies are needed to delineate the differences between in vitro and in vivo differentiation potential of mESCs with respect to contribution to the trophectoderm. Several recent publications point to meta-stable "totipotent" states in mESC, which can be stabilized by alterations in culture conditions (Macfarlan et al., 2012; Morgani et al., 2013); similarly, a recent study has verified totipotency of in vivo derived mouse iPSCs, with the ability to contribute to trophectoderm-derived tissues (Abad et al., 2013). These studies should focus our attention on the still-present gaps in knowledge about toti- and pluripotency in general, and trophectoderm specification in particular. It is imperative that reproductive, stem cell, and developmental biologists forge ahead with these investigations, working together and always keeping an open mind.

\section{Acknowledgements}

This work was supported by funds from a California Institute for Regenerative Medicine New Faculty Award (RN2-00931-1) and the National Institutes of Health (R01HD071100) to M.M.P.

\section{References}

ABAD M., MOSTEIRO L., PANTOJA C., CAÑAMERO M., RAYONT., ORS I., GRAÑA O., MEGÍAS D., DOMÍNGUEZ O., MARTÍNEZ D., MANZANARES M., ORTEGA S., SERRANO M. (2013) Reprogramming in vivo produces teratomas and iPS cells with totipotency features. Nature 502: 340-345.

AMITA M., ADACHI K., ALEXENKO A.P., SINHA S., SCHUST D.J., SCHULZ L.C., ROBERTS R.M. and EZASHI T. (2013) Complete and unidirectional conversion of human embryonic stem cells to trophoblast by BMP4. Proc Natl Acad Sci USA 110: E1212-E1221.

BACZYKD., DUNKC., HUPPERTZB., MAXWELLC., REISTERF., GIANNOULIASD., KINGDOM J.C. (2006) Bi-potential behaviour of cytotrophoblasts in first trimester chorionic villi. Placenta 27: 367-374.

BACZYK D., DREWLO S., PROCTOR L., DUNK C., LYE S. and KINGDOM J. (2009) Glial cell missing-1 transcription factor is required for the differentiation of the human trophoblast. Cell Death Differ 16: 719-727.

BAI Q., ASSOU S., HAOUZI D., RAMIREZ J.M., MONZO C., BECKER F., GERBALCHALOINS., HAMAMAHS. and DE VOSJ. (2012) Dissecting the first transcriptional divergence during human embryonic development. Stem Cell Rev 8: 150-162.

BEDDINGTON R.S., ROBERTSON E.J. (1989) An assessment of the developmental potential of embryonic stem cells in the midgestation mouse embryo. Development 105: 733-737.

BERG D.K., SMITH C.S., PEARTON D.J., WELLS D.N., BROADHURST R., DONNISON M. and PFEFFER P.L. (2011) Trophectoderm lineage determination in cattle. Dev Cell 20: 244-255.

BERNARDO A.S., FAIAL T., GARDNER L., NIAKAN K.K., ORTMANN D., SENNER C.E., CALLERYE.M., TROTTERM.W., HEMBERGERM., SMITHJ.C., BARDWELL L., MOFFETT A. and PEDERSEN R.A. (2011) BRACHYURY and CDX2 mediate BMP-induced differentiation of human and mouse pluripotent stem cells into embryonic and extraembryonic lineages. Cell Stem Cell 9: 144-155.

BILBAN M., TAUBER S., HASLINGER P., POLLHEIMER J., SALEH L., PEHAMBERGER H., WAGNER O., KNÖFLER M. (2010) Trophoblast invasion: assessment of cellular models using gene expression signatures. Placenta 31: 989-996.

BRONS IG, SMITHERS LE, TROTTER MW, RUGG-GUNN P, SUN B, CHUVA DE SOUSA LOPES SM, HOWLETT SK, CLARKSON A, AHRLUND-RICHTER L, PEDERSEN RA, VALLIER L. (2007) Derivation of pluripotent epiblast stem cells from mammalian embryos. Nature 448: 191-195.

BULMER J.N., WILLIAMS P.J. and LASH G.E. (2010) Immune cells in the placental bed. Int J Dev Biol 54: 281-294.

CHAWENGSAKSOPHAK K., DE GRAAFF W., ROSSANT J., DESCHAMPS J. and BECK F. (2004) Cdx2 is essential for axial elongation in mouse development. Proc Natl Acad Sci USA 101: 7641-7645.

CHEN G., YE Z., YU X., ZOU J., MALI P., BRODSKY R.A. and CHENG L. (2008) Trophoblast differentiation defect in human embryonic stem cells lacking PIG-A and GPI-anchored cell-surface proteins. Cell Stem Cell 2: 345-355.

CHEN Y., WANG K., CHANDRAMOULI G.V., KNOTT J.G. and LEACH R. (2013) Trophoblast lineage cells derived from human induced pluripotent stem cells. Biochem Biophys Res Commun 436: 677-684.

CHOI H.J., SANDERS T.A., TORMOS K.V., AMERI K., TSAI J.D., PARK A.M., GONZALEZ J., RAJAH A.M., LIU X., QUINONEZ D.M., RINAUDO P.F., MALTEPE E. (2013) ECM-dependent HIF induction directs trophoblast stem cell fate via LIMK1-mediated cytoskeletal rearrangement. PLoS One 8: e56949.

COLE L.A. (2010) Hyperglycosylated hCG, a review. Placenta 31: 653-664.

COLE L.A. (2012) hCG, five independent molecules. Clin Chim Acta 413: 48-65. 
DAMSKY C.H., FITZGERALD M.L. and FISHER S.J. (1992) Distribution patterns of extracellular matrix components and adhesion receptors are intricately modulated during first trimester cytotrophoblast differentiation along the invasive pathway, in vivo. J Clin Invest 89: 210-222.

DASP., EZASHIT., SCHULZL.C., WESTFALLS.D., LIVINGSTONK.A. and ROBERTS R.M. (2007) Effects of FGF2 and oxygen in the BMP4-driven differentiation of trophoblast from human embryonic stem cells. Stem Cell Res 1: 61-74.

DE LOS ANGELES A., LOH Y.H., TESAR P.J. and DALEY G.Q. (2012) Accessing naive human pluripotency. Curr Opin Genet Dev 22: 272-282.

DI-GREGORIO A., SANCHO M., STUCKEY D.W., CROMPTON L.A., GODWIN J., MISHINAY. and RODRIGUEZT.A. (2007) BMP signalling inhibits premature neural differentiation in the mouse embryo. Development 134: 3359-3369.

DRUKKERM., TANG C., ARDEHALIR., RINKEVICHY., SEITAJ., LEEA.S., MOSLEY A.R., WEISSMAN I.L. and SOEN Y. (2012) Isolation of primitive endoderm, mesoderm, vascular endothelial and trophoblast progenitors from human pluripotent stem cells. Nat Biotechnol 30: 531-542.

ERB T.M., SCHNEIDER C., MUCKO S.E., SANFILIPPO J.S., LOWRY N.C., DESA M.N., MANGOUBI R.S., LEUBA S.H. and SAMMAK P.J. (2011) Paracrine and epigenetic control of trophectoderm differentiation from human embryonic stem cells: the role of bone morphogenic protein 4 and histone deacetylases. Stem Cells Dev 20: 1601-1614.

ERLEBACHER A., PRICE K.A. and GLIMCHER L.H. (2004) Maintenance of mouse trophoblast stem cell proliferation by TGF-beta/activin. Dev Biol 275: 158-169.

EZASHI T., TELUGU B.P. and ROBERTS R.M. (2012) Model systems for studying trophoblast differentiation from human pluripotent stem cells. Cell Tissue Res 349: 809-824

FERRETTI C, BRUNI L, DANGLES-MARIE V, PECKING AP, BELLET D. (2007) Molecular circuits shared by placental and cancer cells, and their implications in the proliferative, invasive and migratory capacities of trophoblasts. Hum Reprod Update 13: 121-141.

FORBES K., WESTWOOD M., BAKER P.N., APLIN J.D. (2008) Insulin-like growth factor I and II regulate the life cycle of trophoblast in the developing human placenta. Am J Physiol Cell Physiol 294: C1313-C1322.

FOURNIER T., GUIBOURDENCHE J., HANDSCHUH K., TSATSARIS V., RAUWEL B., DAVRINCHE C. and EVAIN-BRION D. (2011) PPARgamma and human trophoblast differentiation. J Reprod Immunol 90: 41-49.

FUJIMOTO S., HAMASAKI K., UEDA H. and KAGAWA H. (1986) Immunoelectron microscope observations on secretion of human placental lactogen (hPL) in the human chorionic villi. Anat Rec 216: 68-72.

GELLERSEN B., BROSENS I.A. and BROSENS J.J. (2007) Decidualization of the human endometrium: mechanisms, functions, and clinical perspectives. Semin Reprod Med 25: 445-453.

GENBACEV O., DONNE M., KAPIDZIC M., GORMLEY M., LAMB J., GILMORE J., LAROCQUE N., GOLDFIEN G., ZDRAVKOVIC T., MCMASTER M.T. and FISHER S.J. (2011) Establishment of human trophoblast progenitor cell lines from the chorion. Stem Cells 29: 1427-1436

GIAKOUMOPOULOS M. and GOLOS T.G. (2013) Embryonic stem cell-derived trophoblast differentiation: a comparative review of the biology, function, and signaling mechanisms. J Endocrinol 216: R33-R45

GRAHAM C.H., LYSIAK J.J., MCCRAE K.R., LALA P.K. (1992) Localization of transforming growth factor-beta at the human fetalematernal interface: role in trophoblast growth and differentiation. Biol Reprod 46: 561-572.

GUIBOURDENCHE J., HANDSCHUH K., TSATSARIS V., GERBAUD P., LEGUY M.C., MULLER F., BRION D.E. and FOURNIER T. (2010) Hyperglycosylated hCG is a marker of early human trophoblast invasion. J Clin Endocrinol Metab 95: E240-E244.

HANDSCHUH K., GUIBOURDENCHE J., TSATSARIS V., GUESNON M., LAURENDEAU I., EVAIN-BRION D. and FOURNIER T. (2007) Human chorionic gonadotropin produced by the invasive trophoblast but not the villous trophoblast promotes cell invasion and is down-regulated by peroxisome proliferator-activated receptor-gamma. Endocrinology 148: 5011-5019.

HAYASHIY, FURUE MK, TANAKAS, HIROSEM, WAKISAKAN, DANNOH, OHNUMA K, OEDA S, AIHARA Y, SHIOTA K, OGURAA, ISHIURA S, ASASHIMA M. (2010) BMP4 induction of trophoblast from mouse embryonic stem cells in defined culture conditions on laminin. In vitro Cell Dev Biol Anim 46: 416-430.

HEMBERGER M., UDAYASHANKAR R., TESAR P., MOORE H. and BURTON G.J.
(2010) ELF5-enforced transcriptional networks define an epigenetically regulated trophoblast stem cell compartment in the human placenta. Hum Mol Genet 19 : 2456-2467.

INMAN K.E. and DOWNS K.M. (2006) Localization of Brachyury (T) in embryonic and extraembryonic tissues during mouse gastrulation. Gene ExprPatterns 6: 783-793.

JAMES J.L., CARTER A.M. and CHAMLEY L.W. (2012a) Human placentation from nidation to 5 weeks of gestation. Part I: What do we know about formative placenta development following implantation? Placenta 33: 327-334.

JAMES J.L., CARTER A.M. and CHAMLEY L.W. (2012b) Human placentation from nidation to 5 weeks of gestation. Part II: Tools to model the crucial first days. Placenta 33: 335-342.

JANATPOUR M.J., MCMASTER M.T., GENBACEV O., ZHOU Y., DONG J., CROSS J.C., ISRAELM.A. and FISHER S.J. (2000) Id-2 regulates critical aspects of human cytotrophoblast differentiation, invasion and migration. Development 127:549-558.

JOHN R. and HEMBERGER M. (2012) A placenta for life. Reprod Biomed Online 25: 5-11.

KISHIGAMI S. and MISHINAY. (2005) BMP signaling and early embryonic patterning Cytokine Growth Factor Rev 16: 265-278.

KNOFLER M. (2010) Critical growth factors and signalling pathways controlling human trophoblast invasion. Int J Dev Biol 54: 269-280.

KNÖFLER M, POLLHEIMER J. (2013) Human placental trophoblast invasion and differentiation: a particular focus on Wnt signaling. Front Genet 4: 190.

LEE Y., KIM K.R., MCKEON F., YANG A., BOYD T.K., CRUM C.P. and PARAST M.M. (2007) A unifying concept of trophoblastic differentiation and malignancy defined by biomarker expression. Hum Pathol 38: 1003-1013.

LI Y., MORETTO-ZITA M., SONCIN F., WAKELAND A., WOLFE L., LEON-GARCIA S., PANDIAN R., PIZZO D., CUI L., NAZOR K., LORING J.F., CRUM C.P., LAURENT L.C. and PARAST M.M. (2013) BMP4-directed trophoblast differentiation of human embryonic stem cells is mediated through a DeltaNp63+ cytotrophoblast stem cell state. Development 140: 3965-3976.

LICHTNER B., KNAUS P., LEHRACH H. and ADJAYE J. (2013) BMP10 as a potent inducer of trophoblast differentiation in human embryonic and induced pluripotent stem cells. Biomaterials 34: 9789-9802.

MACFARLAN T.S., GIFFORD W.D., DRISCOLL S., LETTIERI K., ROWE H.M., BONANOMID., FIRTHA., SINGERO., TRONO D., PFAFF S.L. (2012) Embryonic stem cell potency fluctuates with endogenous retrovirus activity. Nature 487:57-63.

MARCHAND M., HORCAJADAS J.A., ESTEBAN F.J., MCELROY S.L., FISHER S.J. and GIUDICE L.C. (2011) Transcriptomic signature of trophoblast differentiation in a human embryonic stem cell model. Biol Reprod 84: 1258-1271.

MATSUURA K, JIGAMI T, TANIUE K, MORISHITAY, ADACHI S, SENDA T, NONAKA A, ABURATANI H, NAKAMURA T, AKIYAMA T. (2011) Identification of a link between Wnt/ $\beta$-catenin signalling and the cell fusion pathway. Nat Commun 2: 548

MEINHARDT G., HUSSLEIN P. and KNOFLER M. (2005) Tissue-specific and ubiquitous basic helix-loop-helix transcription factors in human placental trophoblasts. Placenta 26: 527-539.

MISHINA Y., SUZUKI A., UENO N. and BEHRINGER R.R. (1995) Bmpr encodes a type I bone morphogenetic protein receptor that is essential for gastrulation during mouse embryogenesis. Genes Dev 9: 3027-3037.

MORGANI S.M., CANHAM M.A., NICHOLS J., SHAROV A.A., MIGUELES R.P., KO M.S., BRICKMAN J.M. (2013) Totipotent embryonic stem cells arise in groundstate culture conditions. Cell Rep 3: 1945-1957.

MUROHASHI M., NAKAMURAT., TANAKAS., ICHISE T., YOSHIDAN., YAMAMOTO T., SHIBUYAM., SCHLESSINGER J. and GOTOHN. (2010)An FGF4-FRS2alpha$\mathrm{Cdx} 2$ axis in trophoblast stem cells induces Bmp4 to regulate proper growth of early mouse embryos. Stem Cells 28: 113-121.

MURTHI P., KALIONIS B., COCQUEBERT M., RAJARAMAN G., CHUI A., KEOGH R.J., EVAIN-BRION D. and FOURNIER T. (2013) Homeobox genes and downstream transcription factor PPARgamma in normal and pathological human placental development. Placenta 34: 299-309.

NAGYA., GOCZA E., DIAZE.M., PRIDEAUX V.R., IVÁNYIE., MARKKULAM., ROS SANT J. (1990) Embryonic stem cells alone are able to support fetal development in the mouse. Development 110: 15-21.

NIAKAN K.K. and EGGAN K. (2013) Analysis of human embryos from zygote to blastocyst reveals distinct gene expression patterns relative to the mouse. Dev Biol 375: 54-64. 
NICHOLS J. and SMITH A. (2012) Pluripotency in the embryo and in culture. Cold Spring Harb Perspect Biol 4: a008128.

OKAMOTO I., PATRAT C., THEPOT D., PEYNOT N., FAUQUE P., DANIEL N., DIABANGOUAYA P., WOLF J.P., RENARD J.P., DURANTHON V. and HEARD E. (2011) Eutherian mammals use diverse strategies to initiate X-chromosome inactivation during development. Nature 472: 370-374.

POLLHEIMER J, KNÖFLER M. (2005) Signalling pathways regulating the invasive differentiation of human trophoblasts: a review. Placenta 26: S21-S30.

RIVERA-PEREZ J.A. and MAGNUSON T. (2005) Primitive streak formation in mice is preceded by localized activation of Brachyury and Wnt3. Dev Biol 288: 363-371.

RIZZO R, VERCAMMEN M, VAN DE VELDE H, HORN PA, REBMANN V. (2011) The importance of HLA-G expression in embryos, trophoblast cells, and embryonic stem cells. Cell Mol Life Sci 68: 341-352.

ROBERTS R.M. and FISHER S.J. (2011) Trophoblast stem cells. Biol Reprod 84: 412-421.

ROSSANTJ. (2007) Stem cells and lineage development in the mammalian blastocyst. Reprod Fertil Dev 19: 111-118.

RUSS A.P., WATTLER S., COLLEDGE W.H., APARICIO S.A., CARLTON M.B., PEARCE J.J., BARTON S.C., SURANI M.A., RYAN K., NEHLS M.C., WILSON V. and EVANS M.J. (2000) Eomesodermin is required for mouse trophoblast development and mesoderm formation. Nature 404: 95-99.

SCHENKE-LAYLAND K., ANGELIS E., RHODES K.E., HEYDARKHAN-HAGVALL S., MIKKOLA H.K., MACLELLAN W.R. (2007) Collagen IV induces trophoectoderm differentiation of mouse embryonic stem cells. Stem Cells 25: 1529-1538.

SOARES M.J., CHAKRABORTY D., RENAUD S.J., KUBOTA K., BU P., KONNO T. and RUMI M.A. (2012) Regulatory pathways controlling the endovascular invasive trophoblast cell lineage. J Reprod Dev 58: 283-287.

SUDHEER S., BHUSHAN R., FAULER B., LEHRACH H. and ADJAYE J. (2012) FGF inhibition directs BMP4-mediated differentiation of human embryonic stem cells to syncytiotrophoblast. Stem Cells Dev 21: 2987-3000.

SUZUKI Y., KOSHI K., IMAI K., TAKAHASHI T., KIZAKI K. and HASHIZUME K. (2011) Bone morphogenetic protein 4 accelerates the establishment of bovine trophoblastic cell lines. Reproduction 142: 733-743.
TACHE V., CIRIC A., MORETTO-ZITA M., LI Y., PENG J., MALTEPE E., MILSTONE D.S., PARAST M.M. (2013) Hypoxia and Trophoblast Differentiation: A Key Role for PPAR $\gamma$. Stem Cells Dev 22: 2815-2824.

TAN T., TANG X., ZHANG J., NIU Y., CHEN H., LI B., WEI Q. and JI W. (2011) Generation of trophoblast stem cells from rabbit embryonic stem cells with BMP4. PLoS One 6: e17124.

TANAKA S., KUNATH T., HADJANTONAKIS A.K., NAGY A. and ROSSANT J. (1998) Promotion of trophoblast stem cell proliferation by FGF4. Science282:2072-2075.

TESAR PJ, CHENOWETH JG, BROOK FA, DAVIES TJ, EVANS EP, MACK DL, GARDNER RL, MCKAY RD. (2007) New cell lines from mouse epiblast share defining features with human embryonic stem cells. Nature 448: 196-199.

WATSON A.G., DE LAHUNTA A. and EVANS H.E. (1986) Prenatal development of the composite occipito-atlanto-axial synovial joint cavity in the dog. Anat Rec 216: 423-433.

WORTMAN A.C. and ALEXANDER J.M. (2013) Placenta accreta, increta, and percreta. Obstet Gynecol Clin North Am 40: 137-154.

WU Z., ZHANG W., CHEN G., CHENG L., LIAO J., JIA N., GAO Y., DAI H., YUAN J. and XIAO L. (2008) Combinatorial signals of activin/nodal and bone morphogenic protein regulate the early lineage segregation of human embryonic stem cells. $J$ Biol Chem 283: 24991-5002.

XU R.H., CHEN X., LI D.S., LI R., ADDICKS G.C., GLENNON C., ZWAKA T.P. and THOMSON J.A. (2002) BMP4 initiates human embryonic stem cell differentiation to trophoblast. Nat Biotechnol 20: 1261-1264.

YING QL, NICHOLS J, CHAMBERS I, SMITHA. (2003) BMP induction of Id proteins suppresses differentiation and sustains embryonic stem cell self-renewal in collaboration with STAT3. Cell 115: 281-292.

YUP., PAN G., YU J. and THOMSON J.A. (2011) FGF2 sustains NANOG and switches the outcome of BMP4-induced human embryonic stem cell differentiation. Cell Stem Cell 8: 326-334.

ZHANG P., LI J., TAN Z., WANG C., LIU T., CHEN L., YONG J., JIANG W., SUN X., DU L., DING M. and DENG H. (2008) Short-term BMP-4 treatment initiates mesoderm induction in human embryonic stem cells. Blood 111: 1933-1941. 


\section{Further Related Reading, published previously in the Int. J. Dev. Biol.}

Critical growth factors and signalling pathways controlling human trophoblast invasion.

Martin Knöfler.

Int. J. Dev. Biol. (2010) 54: 269-280.

Developmental cell biology of human villous trophoblast: current research problems John D. Aplin

Int. J. Dev. Biol. (2010) 54: 323-329

http://dx.doi.org/10.1387/ijdb.082759ja

Porcine induced pluripotent stem cells analogous to naïve and primed embryonic stem cells of the mouse

Bhanu Prakash V.L. Telugu, Toshihiko Ezashi and R. Michael Roberts

Int. J. Dev. Biol. (2010) 54: 1703-1711

http://dx.doi.org/10.1387/ijdb.103200bt

Reprogramming cell fate to pluripotency: the decision-making signalling pathways Daniela Sanges and Maria-Pia Cosma Int. J. Dev. Biol. (2010) 54: 1575-1587

http://dx.doi.org/10.1387/ijdb.103190ds

Pluripotency and differentiation in embryos and stem cells - Pavia, 17-18 January 2008 James A. Adjaye, Anne G. Byskov, Jose B. Cibelli, Ruggero De Maria, Stephen Minger, Maurilio Sampaolesi, Giuseppe Testa, Catherine Verfaillie, Magdalena Zernicka-Goetz, Hans Schöler, Michele Boiani, Nicola Crosetto and Carlo A. Redi

Int. J. Dev. Biol. (2008) 52: 801-809

http://dx.doi.org/10.1387/ijdb.082695ja

5 yr ISI Impact Factor $(2011)=2.959$
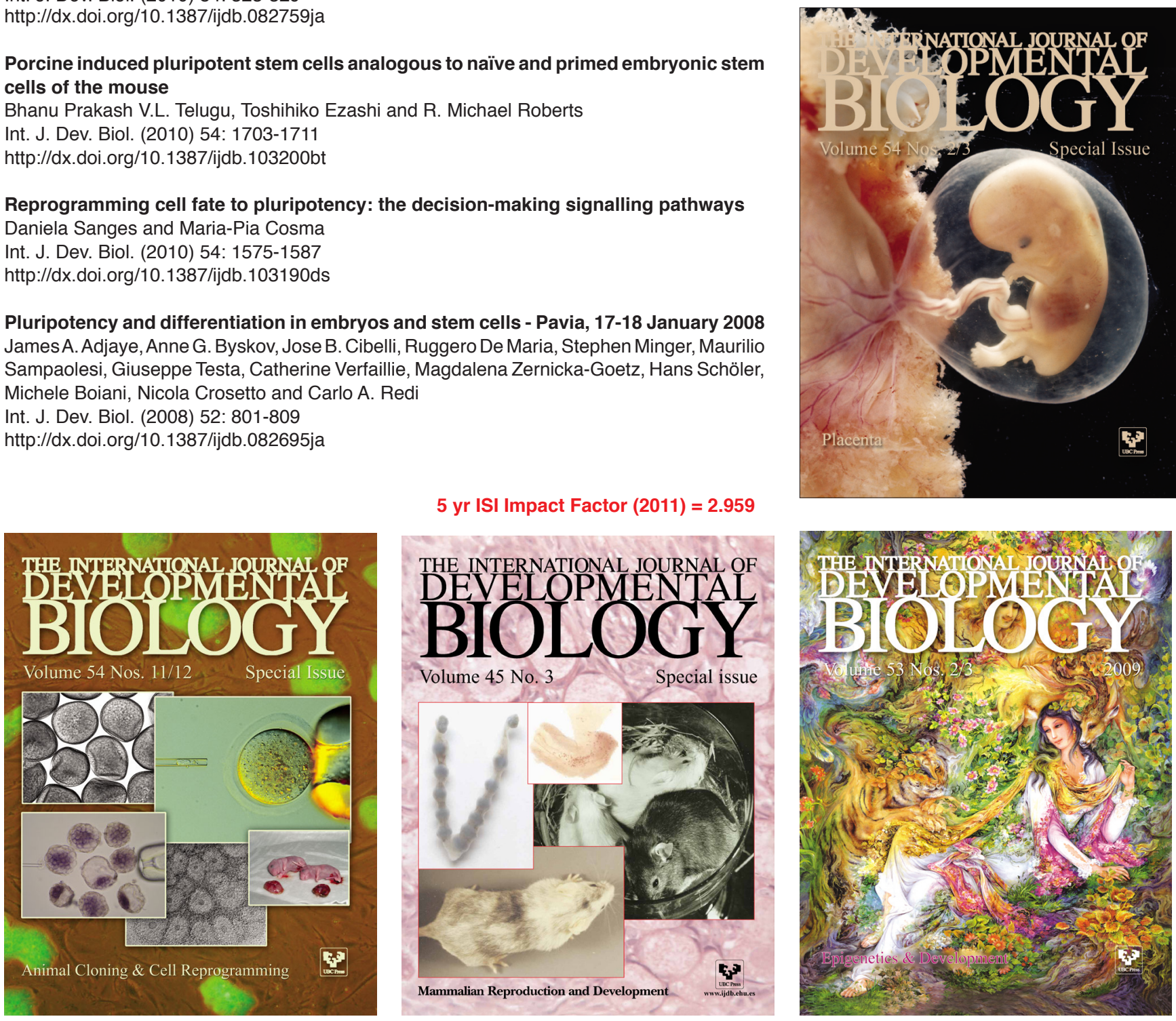